\title{
Ribosome-Mediated Synthesis of Natural Product-Like Peptides Via Cell-Free Translation
}

\author{
Rumit Maini ${ }^{1}$, Shiori Umemoto ${ }^{1}$, Hiroaki Suga ${ }^{1,2}$ \\ ${ }^{1}$ Department of Chemistry, Graduate School of Science, The University of Tokyo, 7-3-1 \\ Hongo, Bunkyo-ku, Tokyo 113-0033, Japan \\ ${ }^{2}$ JST, CREST, 7-3-1 Hongo, Bunkyo-ku, Tokyo 113-0033, Japan
}

$\dagger$ †o whom correspondence should be addressed. E-mail: hsuga@chem.s.u-tokyo.ac.jp 


\begin{abstract}
Peptide natural products (PNPs) represent a unique class of compounds known for their fascinating structural motifs with important biological activities. Lately, PNPs have garnered a lot of interest for their application in drug discovery. Nevertheless, lack of diversity oriented synthetic/biosynthetic platforms to generate large natural product-like libraries has limited their development as peptide therapeutics. The promiscuity of cell-free translation has allowed for the synthesis of artificial PNPs having complex structural features. Modified cell-free translation systems coupled with the display technologies have generated diverse natural product-like peptide libraries and led to the discovery of several biologically active molecules. Such technologies have drastically decreased the time to obtain peptide drug leads and therefore, revolutionized the field of peptide drug discovery. In this account, we review recent developments in the synthesis of natural product-like peptides via cell-free translation.
\end{abstract}




\section{Introduction}

Peptide natural products (PNPs) possess interesting structural features, which make them great therapeutic agents and allow them to modulate difficult 'undruggable' targets not easily accessible by small molecules. Some common structural designs observed in PNPs are ring topologies, non-standard amino acids (nsAAs) including $N$-methyl amino acids, D-amino acids, amino acids with noncanonical side chains, $\beta$ - $/ \gamma$-amino acids and backbone heterocyclic motifs such as oxazolines and thiazolines (Figure 1). In the past decade, substantial research efforts were dedicated to generate diverse and large set of peptide libraries having either natural product-like motifs or novel architectures [1]. Genetic code manipulation approaches and chemical post-translational modifications allowed phage and mRNA display technologies to revolutionize the field of peptide therapeutics [1,2]. Cell-free translation system integrated with mRNA display technology [3] has provided several potent bioactive natural product-like peptides with high target-binding affinities $[1,2,4]$. Moreover, a recently described modified translation/mRNA display format [5] has significantly decreased the time and efforts spent for the search of bioactive peptide sequences. Moving beyond the drug discovery application, coupled translation-selection systems have generated peptides, which were also useful as cocrystallization ligands [6], fluorogenic peptide aptamers [7,8] and fluorescent probes

[9]. Clearly, such discoveries were made possible by the ability of cell-free translation to incorporate diverse structural motifs observed in PNPs into peptides. In this review, we will focus on different strategies employed for the ribosomal synthesis of natural product-like peptides using cell-free translation systems and their applications.

\section{Macrocyclization}

A prevalent structural motif among PNPs is a ring topology (macrocyclic structures), which decreases the number of conformations available for a peptide. Such a structural rigidity decreases the entropic cost to adopt the bioactive conformation and thus, improves target-binding affinity [10,11]. Moreover, macrocyclization distorts the alignment of residues around an amide bond, which in turn decreases the chance to be recognized by peptidases and therefore, potentially increases resistance against proteolysis. In addition, some studies have shown that cyclization could improve passive membrane permeability by promoting intra- 
molecular interactions $[12,13]$. Due to these advantages, methodologies for peptide cyclization have been extensively explored $[4,14,15]$.

Cysteine-mediated macrocyclization strategies, where the nucleophilic reactivity of sulfhydryl group is exploited, are frequently applied. Inspired by the posttranslational modifications and cyclization in lantipeptide biosynthesis [16], Szostak and co-workers developed a cyclization method to produce lantipeptide analogues (Figure 2a) [17]. Using in vitro translation, 4-selenolysine (1, Figure 3a) and 4-selenoisoleucine amino acids were incorporated into a ribosomal peptide and subsequently oxidized by hydrogen peroxide to generate dehydroalanine (Dha) and dehydrobutyrine (Dhb), respectively. Upon deprotection of a cysteine, a selective nucleophilic attack on a more reactive Dha over Dhb residue afforded desired macrocyclization (lanthioine formation). Afterwards, this strategy was combined with mRNA display to generate a library of functional lantipeptides $\left(10^{11}\right.$ membered library) and a low micromolar $(3 \mu \mathrm{M})$ binder of Sortase A was obtained from the selection [18]. Eventually, Suga and co-workers devised a more versatile strategy involving a reaction between cysteine and the electrophilic carbon of chloroacetyl moiety on the N-terminus of a peptide (figure 2b) [19]. In this work, a custom-made reconstituted cell-free translation system called Flexible In Vitro Translation (FIT) system [3] was used. Central to the FIT system is a ribozyme-mediated aminoacylation of tRNAs (called flexizyme technology) [20,21] and genetic code reprogramming [22,23] for the incorporation of non-canonical amino acids [24]. Methionine residue was removed from the FIT system and initiation event was reprogrammed to accept $N^{\alpha}$-(2-chloroacetyl)-Trp (2, Figure 3a). After translation, spontaneous cyclization occurred between $\mathrm{C}$-terminal cysteine side-chain and Nterminal head of the tryptophan residue (Figure $2 b$ ). Later on, this strategy was integrated into mRNA display format and was called the Random non-standard Peptide Integrated Discovery (RaPID) system [3]. The FIT/RaPID system have been successfully utilized for the construction and screening of large macrocyclic peptide libraries $\left(10^{13}\right)$ to afford active natural product-like molecules, which gave remarkable results as enzymes inhibitors [25,26], modulators of protein-protein interactions [27,28] stable hormone analog [29], protein co-crystallization ligands [30] and fluorescent imaging probe [9].

Bicyclic structures are not common among PNPs. However, larger size bicyclic peptides may give rise to more extensive interactions with their protein 
targets as compared to monocyclic counterparts. In this direction, Suga et al. reported strategies to obtain bicyclic [31] and recently, tricyclic [32] peptides using cell-free translation system. For bicyclization, two orthogonal (intramolecular) reactions were carried out after the ribosomal synthesis of peptide. Using genetic code reprogramming and a modified cell-free translation system (which is now known as the FIT system), 4-(2-chloroacetyl)aminobutyric acid (Cab, 3, Figure 3a) having a cysteine reactive functionality and a cycloaddition reaction pair azidohomoalanine (Aha, 4, Figure 3a) and propargylglycine (Pgl, 5, Figure 3a) were incorporated. Cu (I) mediated click reaction between azide and alkyne side chains led to the first cyclization event, whereas thioether formation between cysteine and Cab residue afforded fully bicyclized peptides [31]. Recently, chemically synthesized bicyclic peptide libraries were employed to select inhibitors of protein-protein interaction [33]. On the other hand, utilizing 1,3,5-tris(bromomethyl)-benzene (TBMB) mediated cyclization of phage displayed peptide libraries (Figure 2c), Heinis and Winter reported a potent bicyclic peptide inhibitor of human urokinase-type plasminogen activator $\left(K_{\mathrm{d}}=53 \mathrm{nM}\right)$ [34] having improved biological activity over previously reported monocyclic inhibitors. [35]

Iwasaki et al. demonstrated that the $N^{\alpha}$-(2-chloroacetyl) group on initiator amino acid (position 1) in a peptide cyclizes with the nearest cysteine irrespective of the presence of downstream cysteine residues, however it does not react with cysteine present right next (position 2) to the initiator amino acid [36]. Bashiruddin et al. benefitted from this selective cyclization and reported a strategy to obtain tricyclic peptides (Figure 2d) [36]. In this account, a peptide containing $N$-chloroacetyl- ${ }^{\mathrm{D}} \operatorname{Trp}$ at the $\mathrm{N}$-terminus and four cysteine residues was translated. After ribosome-mediated translation of the desired peptide, first cyclization event occurred between the $\mathrm{N}$ chloroacetyl group and a downstream cysteine, leaving cysteine at position 2 of the peptide unreacted. Subsequently, addition of 1,3,5-tris(bromomethyl)-benzene (TBMB) led to two cyclization events involving three cysteine residues, which afforded a fused tricyclic peptide (Figure 2d).

\section{D-amino acids}

D-amino acids are often found in PNPs and known to increase serum stability of a peptide due to decrease in proteolytic degradation [37] and induce turn 
conformations in peptides [38]. Ribosome-mediated incorporation of D-amino acids into peptides was carried out by taking advantage of promiscuous substrate specificity of translation initiation [39,40]. Different $N$-formyl and $N$-acyl-D-aminoacyltRNA $^{\text {fMet }}$ were prepared via aminoacylation carried out by flexizymes. In the absence of methionine, ribosome utilized reprogrammed $\mathrm{RRNA}^{\mathrm{fMet}} \mathrm{s}$ for translation initiation to synthesize peptides bearing D-amino acids in the FIT system [39]. In a very recent application of this approach, a 14-mer macrocyclic peptide having $N$-chloroacetyl${ }^{\mathrm{D}}$ Phe $(\mathbf{6}$, Figure $3 \mathrm{~b})$ residue was selected from a large peptide library, to bind the extracellular domain of EpCAM with a $K_{\mathrm{d}}$ of $1.7 \mathrm{nM}$ and a fluorescent tag enabled the visualization of EpCAM-expressing MCF7 cells [9]. This peptide based fluorescent probe was under $3000 \mathrm{Da}$ and stained every live cell under high cell-density conditions.

Fujino et al. reexamined the elongation efficiency of $19 \mathrm{D}$-amino acid residues by reassigning UCC codon to D-aminoacyl-tRNA ${ }_{\text {GGU }}^{\text {isn }}$ in the FIT system. Twelve D-residues were individually translated in $10 \%$ or higher yields and peptides containing either two D-Ala or D-phe residues ( 7 or 8 , Figure $3 \mathrm{~b}$ ) were also efficiently synthesized [41]. Lately, using in vitro reconstituted dehydrogenases, posttranslational conversion of dehydroalanine into D-alanine was reported [42]. Enzymes NpnM and maltose-binding protein (MBP)-fused NpnA3 were co-expressed in E. coli along with the substrate peptides. NpnM catalyzed the formation of dehydroalanine and dehydrobutyrine residues, whereas NpnA3 selectively reduced dehydroalanine to D-alanine in presence of NADPH.

\section{N-Alkyl Amino Acids}

Another frequently observed structural feature among PNPs is $N$-methylation, where nitrogen atom of an amide bond is methylated [43]. Similar to macrocyclization, it increases conformational rigidity as well as resistance to peptidases. Due to $N$-methylation, amide bond is unable to participate in hydrogen bonding with near by water molecules, which is believed to promote passive membrane permeability [44-46]. Cyclosporin A (Figure 1), an 11-residue cyclic peptide having seven $N$-methylated amide bonds, is the most studied natural cyclic peptide for its good pharmacological properties including cell permeability [12,47]. In nature, $N$-methylated PNPs are not synthesized by the ribosome or derived from 
ribosomally synthesized peptides, rather a large set of multifunctional enzymes working in tandem, called non-ribosomal peptide synthetases (NRPSs), carry out the biosynthesis of $N$-methylated peptides $[48,49]$. Nevertheless, ribosomal acceptance of $N$-methylated amino acids is known for a long time [50]. In addition, ribosomal tolerance of different $N$-methylated amino acids has been evaluated by various research groups [51-53].

Subtelny et al. demonstrated the ribosome-mediated incorporation multiple $N$ methylated amino acids into peptides by chemical methylation of amine on the canonical aminoacyl-tRNAs followed by their use in a cell-free translation system [52]. Although, they produced $N$-methylated peptides with reasonable efficiencies, this methodology suffered with misincorporations and truncated peptide products. In the first example of its kind, Kawakami et al. reported the incorporation of up to eight consecutive $N$-methyl amino acids (including 9-12, Figure 3c) into peptides using the FIT system [53]. Moreover, macrocyclization of $N$-methylated peptides was also demonstrated, which enabled the preparation and application of natural-product like macrocyclic peptide libraries to search for biologically active molecules with interesting pharmacological properties. So far, two examples of $N$-methylated peptide inhibitors are reported. First, five $N$-methyl amino acids were included during the preparation of peptide library, thereby screening this library against a ubiquitin ligase E6AP to yield several multiple $N$-methylated macrocyclic peptides (Figure 4 a) with low to sub-nanomolar binding affinities (as low as $K_{\mathrm{d}}=0.6 \mathrm{nM}$ ) [26]. Second, using a slightly different display system called transcription-translation coupled with association of puromycin linker (TRAP) [5], Ishizawa et al. reported a potent $N$ methyl-macrocyclic peptide inhibitor against VEGFR2, a human membrane protein growth factor receptor, with a $K_{\mathrm{d}}$ of $33 \mathrm{nM}$ [54]. To produce more complex $N$ alkylated peptides (known as peptoids) via ribosome synthesis, Kawakami et al. utilized the FIT system to synthesize peptoid-peptide hybrids (Figure 4b) by using non-branched, branched and functionalized alkyl chain substituted $\mathrm{N}$-alkyl amino acid substrates (13-28, figure 3c) [55].

In a latest account, Schwochert et al. chemically synthesized different peptoids and peptoid-peptide hybrids and explored their cell permeable properties [56]. They observed that a strategic peptide to peptoid substitution contributed towards enhanced cell permeability. This report and the remarkable ability of the FIT 
system to incorporated $\mathrm{N}$-alkylated amino acids will attract more interest in peptoidpeptide hybrids.

\section{Other Non-Proteinogenic $\alpha$-Amino Acids}

Incorporation of $\alpha$-amino acids with non-canonical side chains into polypeptides has been periodically explored and applied in drug discovery. Szostak group prepared an mRNA displayed highly reprogrammed cyclic peptide library $\left(10^{13}\right)$ to include 12 non-canonical amino acids (29-40, Figure $\left.3 \mathrm{~d}\right)$ and screened against the protease thrombin [57]. Two macrocyclic peptides with low nanomolar binding affinities were isolated and the non-canonical amino acids were shown to be essential for the biological activity of these peptides.

To search for strong inhibitors against a histone decacetylase SIRT2, Suga lab prepared peptide libraries having a non-canonical amino acid $\mathrm{K}^{\mathrm{Tfa}}(\varepsilon-N$-trifuoroacetyl lysine, 41, Figure 3d) in the randomized region [25]. The selection yielded several peptide inhibitors having a conserved sequence around the 'warhead' amino acid $\mathrm{K}^{\mathrm{Tfa}}$ and bound SIRT2 with 10-100 fold selectivity over SIRT1 and SIRT3. The peptide S2iL5 bound with a $K_{\mathrm{d}}$ value of $1.0 \mathrm{nM}$ and was used as a co-crystallization ligand to successfully obtain the structure of S2iL5 bound SIRT2 [58]. Different peptide binders selected from FIT/RaPID system were also used to explore the structure and functions of various therapeutically relevant proteins $[30,59,60]$. Environment sensitive fluorescent amino acids have been used to study protein structure and functions [61].

In a latest report, Manandhar et al. incorporated an environment sensitive fluorescent NBD (7-nitro-2,1,3-benzoxadiazole) group containing amino acid (42, Figure $3 \mathrm{~d}$ ) into a random peptide library and, by using mRNA display, selected aptamers that bind to verotoxin [7]. One of the peptide (VT4) showed decrease in fluorescence produced by NBD upon binding to verotoxin possibly due to change in peptide conformation. This fluorescent peptide probe can now be used for the detection of verotoxin.

\section{Non-a-Amino Acids}

Other important structural motifs that are known to contribute towards the biological activity of PNPs include non- $\alpha$-amino acids such as $\beta$-amino acids and 
backbone heterocycles (Figure 3e) [62-64]. In general, ribosome-mediated incorporation of $\beta$-amino acids into peptides and proteins has been challenging. However, Suga and Murakami labs successfully demonstrated the ribosome-mediated synthesis of peptides having multiple $\beta$-amino acids (43-58, Figure 3e) by genetic code reassignment coupled with the FIT system [65]. Authors successfully demonstrated the incorporation of up to three different $\beta$-amino acids into peptides (Figure 4c).

Earlier, Hecht group reported ribosomes with mutations in the peptidyltransferase center (PTC) that enabled the incorporation of both aliphatic and aromatic $\beta$-amino acids into a single pre-determined site via suppression of amber stop codon by chemically aminoacylated $\beta$-aminoacyl-tRNA [66-68]. The acceptance and thus incorporation of backbone heterocyclic amino acid analogues including thiazol(in)es and oxazol(in)es into polypeptides by the wild-type ribosomes has not been established yet. However, Maini et al. designed and incorporated a highly fluorescent oxazole amino acid derivative (59, Figure 3e) into green fluorescent protein (GFP) and E coli. dihydrofolate reductase (DHFR) using mutant ribosomes via amber suppression technology [69]. Moreover, a dipeptide residue having a thioamide backbone (60, Figure 3e) was also incorporated into DHFR.

Biosynthetic routes to various ribosomally synthesized and post-translationally modified peptides (RiPPs) including thiazol(in)es and oxazol(in)es containing peptides have been studied extensively. Recently, several labs have reported successful in vitro reconstitution of different enzymes involved in the synthesis of RiPPs and their use for post-translational modification of ribosomally synthesized peptides [70]. While, other labs utilized E. coli for the co-expression of the enzyme of interest and their substrate peptides to synthesize azol(in)e (61 and 62, Figure 3e) based peptides in vitro [70], Goto et al. developed a cell-free translation system called FIT-PatD for the synthesis of PNPs [71]. In this study, translation by the FIT system was coupled with post-translational modifications by recombinant PatD enzyme to synthesize multiple azoline containing peptides (Figure 4d). Adding to the growing list of backbone amino acid incorporated into peptides using the FIT system, Torikai and Suga reported a ribosome-mediated synthesis of macrocyclic peptide (Figure 4e) containing a 12-carbon long polyunsaturated chain, which is a peptide analogue of amphotericin B (an amphiphilic membrane-interacting antifungal natural product) [72]. D-cysteine, but not the L-derivative, having the hydrophobic terpene moiety 
linked to the S-atom was accepted by the ribosome during the translation initiation event. The authors speculated that the long and bulky side chain in the L-cysteine derivative is not accommodated in the P-site, whereas in case of D-cysteine derivative, the side chain may sit in the exit tunnel assisting in a more stable initiation complex.

\section{Conclusion}

Here, we have reviewed the contribution of cell-free translation system to produce large natural product-like peptide libraries and its integration with high throughput screening systems to identify interesting peptide drug leads. Several bioactive molecules against difficult therapeutic targets including kinases, and membrane receptors were discovered by the coupled peptide translation-molecular display/selection systems (for example FIT/RaPID system). Moreover, we also discussed that such systems are not limited to drug discovery, rather are also being applied in structural biology as well as fluorescence imaging. As illustrated by examples, cell-free translation systems such as the FIT system have exhibited remarkable ability to incorporate several prominent structural features found among PNPs into ribosomally synthesized peptides. However, the strategies discuss in this review have only been able to access a small portion of vast chemical space available. Further expansions in peptide translational approaches can potentially yield molecules that may go beyond the scope of nature. More research efforts are required to develop current translation-display systems to directly identify orally bioavailable and cell permeable bioactive peptide molecules.

\section{Acknowledgements}

This work is supported by JST CREST of Molecular Technologies, MEXT P-DIRECT, and AMED Basic Science and Platform Technology Program for Innovative Biological Medicine, to H.S.. 


\section{References and recommended reading}

1. Josephson K, Ricardo A, Szostak JW: mRNA display: From basic principles to macrocycle drug discovery. Drug discovery today (2014) 19:388-399.

2. Passioura T, Katoh T, Goto Y, Suga H: Selection-based discovery of druglike macrocyclic peptides. Annu Rev Biochem (2014) 83:727-752.

3. Hipolito CJ, Suga H: Ribosomal production and in vitro selection of natural product-like peptidomimetics: The FIT and RAPID systems. Curr Opin Chem Biol (2012) 16:196-203.

4. Frost JR, Smith JM, Fasan R: Design, synthesis, and diversification of ribosomally derived peptide macrocycles. Curr Opin Struct Biol (2013) 23:571-580.

5. Ishizawa T, Kawakami T, Reid PC, Murakami H: TRAP display: A high-speed

- selection method for the generation of functional polypeptides. J Am Chem Soc (2013) 135:5433-5440.

An efficient display system is developed, where a polypeptide is linked to its DNA via puromycin linkage instead of $m R N A$. The time required for each selection round using TRAP display is significantly lower than a conventional mRNA display system.

6. Hipolito CJ, Bashiruddin NK, Suga H: Protein cocrystallization molecules

- originating from in vitro selected macrocyclic peptides. Curr Opin Struct Biol (2014) 26:24-31.

Strategies for the development of peptide ligands as protein cocrysrallization molecules using peptide-translation/display systems.

7. Manandhar Y, Bahadur KC, Wang W, Uzawa T, Aigaki T, Ito Y: In vitro selection of a peptide aptamer that changes fluorescence in response to verotoxin. Biotechnol Lett (2015) 37:619-625.

8. Wang W, Uzawa T, Tochio N, Hamatsu J, Hirano Y, Tada S, Saneyoshi H, Kigawa T, Hayashi $N$, Ito $\mathrm{Y}$, Taiji $\mathrm{M}$ et al: A fluorogenic peptide probe developed by in vitro selection using tRNA carrying a fluorogenic amino acid. Chem Commun (Camb) (2014) 50:2962-2964.

9. Iwasaki K, Goto Y, Katoh T, Yamashita T, Kaneko S, Suga H: A fluorescent imaging

- probe based on a macrocyclic scaffold that binds to cellular EpCAM. J Mol Evol (2015) 81:210-217.

Application of macrocyclic peptides discovered by the FIT/RaPID system as fluorescence imaging probes. A Fluorescently labaled peptide was able to specifically stain EpCAM-expressing MCF7 cells.

10. Khan AR, Parrish JC, Fraser ME, Smith WW, Bartlett PA, James MN: Lowering the entropic barrier for binding conformationally flexible inhibitors to enzymes.

Biochemistry (1998) 37:16839-16845. 
11. Mallinson J, Collins I: Macrocycles in new drug discovery. Future Med Chem (2012) 4:1409-1438.

12. Rezai T, Yu B, Millhauser GL, Jacobson MP, Lokey RS: Testing the conformational hypothesis of passive membrane permeability using synthetic cyclic peptide diastereomers. J Am Chem Soc (2006) 128:2510-2511.

13. Hewitt WM, Leung SS, Pye CR, Ponkey AR, Bednarek M, Jacobson MP, Lokey RS: Cell-permeable cyclic peptides from synthetic libraries inspired by natural products. J Am Chem Soc (2015) 137:715-721.

14. Morioka T, Loik ND, Hipolito CJ, Goto Y, Suga H: Selection-based discovery of macrocyclic peptides for the next generation therapeutics. Curr Opin Chem Biol (2015) 26:34-41.

15. Bashiruddin NK, Suga $\mathrm{H}$ : Construction and screening of vast libraries of natural product-like macrocyclic peptides using in vitro display technologies. Curr Opin Chem Biol (2015) 24:131-138.

16. Knerr PJ, van der Donk WA: Discovery, biosynthesis, and engineering of lantipeptides. Annu Rev Biochem (2012) 81:479-505.

17. Seebeck FP, Ricardo A, Szostak JW: Artificial lantipeptides from in vitro translation. Chemical Communications (2011) 47:6141-6143.

18. Hofmann FT, Szostak JW, Seebeck FP: In vitro selection of functional lantipeptides. J Am Chem Soc (2012) 134:8038-8041.

19. Goto Y, Ohta A, Sako Y, Yamagishi Y, Murakami H, Suga H: Reprogramming the translation initiation for the synthesis of physiologically stable cyclic peptides. ACS Chem Biol (2008) 3:120-129.

20. Goto $\mathrm{Y}$, Suga $\mathrm{H}$ : Flexizymes as a tRNA acylation tool facilitating genetic code reprogramming. Methods in molecular biology (Clifton, NJ) (2012) 848:465-478.

21. Passioura T, Suga H: Flexizymes, their evolutionary history and diverse utilities. Aminoacyl-Trna Synthetases in Biology and Medicine (2014) 344:331-345.

22. Passioura T, Suga H: Flexizyme-mediated genetic reprogramming as a tool for noncanonical peptide synthesis and drug discovery. Chemistry (Weinheim an der Bergstrasse, Germany) (2013) 19:6530-6536.

23. Terasaka $\mathrm{N}$, Suga $\mathrm{H}$ : Flexizymes-facilitated genetic code reprogramming leading to the discovery of drug-like peptides. Chemistry Letters (2013).

24. Goto $\mathrm{Y}$, Katoh $\mathrm{T}$, Suga $\mathrm{H}$ : Flexizymes for genetic code reprogramming. Nat Protoc (2011) 6:779-790. 
25. Morimoto J, Hayashi Y, Suga H: Discovery of macrocyclic peptides armed with a mechanism-based warhead: Isoform-selective inhibition of human deacetylase sirt2. Angew Chem Int Ed Engl (2012) 51:3423-3427.

26. Yamagishi Y, Shoji I, Miyagawa S, Kawakami T, Katoh T, Goto Y, Suga H: Natural product-like macrocyclic $n$-methyl-peptide inhibitors against a ubiquitin ligase uncovered from a ribosome-expressed de novo library. Chem Biol (2011) 18:1562-1570.

27. Ito K, Sakai K, Suzuki Y, Ozawa N, Hatta T, Natsume T, Matsumoto K, Suga H: Artificial human met agonists based on macrocycle scaffolds. Nature communications (2015) 6:6373.

28. Bayo-Puxan N, Rodriguez-Mias R, Goldflam M, Kotev M, Ciudad S, Hipolito CJ, Varese M, Suga H, Campos-Olivas R, Barril X, Guallar V et al: Combined use of oligopeptides, fragment libraries, and natural compounds: A comprehensive approach to sample the druggability of vascular endothelial growth factor. ChemMedChem (2015).

29. Sako Y, Goto Y, Murakami H, Suga H: Ribosomal synthesis of peptidase-resistant peptides closed by a nonreducible inter-side-chain bond. ACS Chem Biol (2008) 3:241-249.

30. Tanaka Y, Hipolito CJ, Maturana AD, Ito K, Kuroda T, Higuchi T, Katoh T, Kato HE, Hattori M, Kumazaki K, Tsukazaki T et al: Structural basis for the drug extrusion mechanism by a mate multidrug transporter. Nature (2013) 496:247-251.

31. Sako Y, Morimoto J, Murakami H, Suga H: Ribosomal synthesis of bicyclic peptides via two orthogonal inter-side-chain reactions. J Am Chem Soc (2008) 130:7232-7234.

32. Bashiruddin NK, Nagano M, Suga H: Synthesis of fused tricyclic peptides using a

- reprogrammed translation system and chemical modification. Bioorg Chem (2015) 61:45-50.

A first example of the synthesis of tricyclic peptides via cell-free translation. A liner peptide having an $\mathrm{N}$-chloroacetyl-initiator amino acid and four down stream cysteines is translated using the FIT system. A spontaneous intramolecular cyclization between $\mathrm{N}$-chloroacetyl group and cysteine residue followed by subsequent cyclization events by the addition of 1,3,5-tris(bromomethyl)benzene produces the fused tricyclic peptide.

33. Lian W, Upadhyaya P, Rhodes CA, Liu Y, Pei D: Screening bicyclic peptide libraries for protein-protein interaction inhibitors: Discovery of a tumor necrosis factor-alpha antagonist. J Am Chem Soc (2013) 135:11990-11995.

34. Angelini A, Cendron L, Chen S, Touati J, Winter G, Zanotti G, Heinis C: Bicyclic peptide inhibitor reveals large contact interface with a protease target. ACS Chem Biol (2012) 7:817-821. 
35. Zhao G, Yuan C, Wind T, Huang Z, Andreasen PA, Huang M: Structural basis of specificity of a peptidyl urokinase inhibitor, upain-1. J Struct Biol (2007) 160:110.

36. Iwasaki K, Goto $\mathrm{Y}$, Katoh $\mathrm{T}$, Suga H: Selective thioether macrocyclization of peptides having the $\boldsymbol{N}$-terminal 2-chloroacetyl group and competing two or three cysteine residues in translation. Organic \& Biomolecular Chemistry (2012) 10:5783-5786.

37. Hong SY, Oh JE, Lee KH: Effect of D-amino acid substitution on the stability, the secondary structure, and the activity of membrane-active peptide. Biochem Pharmacol (1999) 58:1775-1780.

38. Imperiali B, Moats RA, Fisher SL, Prins TJ: A conformational study of peptides with the general structure Ac-L-xaa-Pro-D-xaa-L-xaa- $\mathrm{NH}_{2}$ : Spectroscopic evidence for a peptide with significant .Beta.-turn character in water and in dimethyl sulfoxide. J Am Chem Soc (1992) 114:3182-3188.

39. Goto $\mathrm{Y}$, Murakami $\mathrm{H}$, Suga $\mathrm{H}$ : Initiating translation with D-amino acids. $R N A$ (New York, NY) (2008) 14:1390-1398.

40. Kawakami T, Murakami H, Suga H: Ribosomal synthesis of polypeptoids and peptoid-peptide hybrids. J Am Chem Soc (2008) 130:16861-16863.

41. Fujino $T$, Goto $Y$, Suga $H$, Murakami H: Reevaluation of the D-amino acid - compatibility with the elongation event in translation. J Am Chem Soc (2013)

? 135:1830-1837.

In this report, ribosomal bias against $\mathrm{D}$-amino acid during translation elongation was challenged and the incorporation of different $D$-amino acids into peptide using the FIT system was successfully demonstrated.

42. Yang $X$, van der Donk WA: Post-translational introduction of D-alanine into ribosomally synthesized peptides by the dehydroalanine reductase npnj. Journal of the American Chemical Society (2015) 137:12426-12429.

43. Chatterjee J, Gilon C, Hoffman A, Kessler H: $\mathbf{N}$-methylation of peptides: A new perspective in medicinal chemistry. Accounts of chemical research (2008) 41:1331-1342.

44. Beck JG, Chatterjee J, Laufer B, Kiran MU, Frank AO, Neubauer S, Ovadia O, Greenberg S, Gilon C, Hoffman A, Kessler H: Intestinal permeability of cyclic peptides: Common key backbone motifs identified. J Am Chem Soc (2012) 134:12125-12133.

45. Frankel A, Millward SW, Roberts RW: Encodamers: Unnatural peptide oligomers encoded in RNA. Chem Biol (2003) 10:1043-1050. 
46. Ovadia O, Greenberg S, Chatterjee J, Laufer B, Opperer F, Kessler H, Gilon C, Hoffman A: The effect of multiple $\boldsymbol{N}$-methylation on intestinal permeability of cyclic hexapeptides. Mol Pharm (2011) 8:479-487.

47. Ahlbach CL, Lexa KW, Bockus AT, Chen V, Crews P, Jacobson MP, Lokey RS: Beyond cyclosporine A: Conformation-dependent passive membrane permeabilities of cyclic peptide natural products. Future Med Chem (2015) 7:2121-2130.

48. Finking R, Marahiel MA: Biosynthesis of nonribosomal peptides. Annu Rev Microbiol (2004) 58:453-488.

49. Sieber SA, Marahiel MA: Molecular mechanisms underlying nonribosomal peptide synthesis: Approaches to new antibiotics. Chem Rev (2005) 105:715738.

50. Ellman JA, Mendel D, Schultz PG: Site-specific incorporation of novel backbone structures into proteins. Science (1992) 255:197-200.

51. Merryman C, Green R: Transformation of aminoacyl tRNAs for the in vitro selection of "drug-like" molecules. Chem Biol (2004) 11:575-582.

52. Subtelny AO, Hartman MC, Szostak JW: Ribosomal synthesis of $\boldsymbol{N}$-methyl peptides. J Am Chem Soc (2008) 130:6131-6136.

53. Kawakami T, Murakami $H$, Suga $H$ : Messenger RNA-programmed incorporation of multiple $\mathbf{N}$-methyl-amino acids into linear and cyclic peptides. Chem Biol (2008).

54. Kawakami T, Ishizawa T, Fujino T, Reid PC, Suga H, Murakami H: In vitro selection of multiple libraries created by genetic code reprogramming to discover macrocyclic peptides that antagonize VEGFR2 activity in living cells. ACS Chem Biol (2013) 8:1205-1214.

55. Kawakami T, Murakami H, Suga $\mathrm{H}$ : Ribosomal synthesis of polypeptoids and peptoid-peptide hybrids. J Am Chem Soc (2008) 130:16861-16863.

56. Schwochert J, Turner R, Thang M, Berkeley RF, Ponkey AR, Rodriguez KM, Leung

- SS, Khunte B, Goetz G, Limberakis C, Kalgutkar AS et al: Peptide to peptoid substitutions increase cell permeability in cyclic hexapeptides. Organic letters (2015) 17:2928-2931.

Effect of peptide to peptoid substitutions on the passive membrane permeability of chemically synthesized cyclic peptides is systematically evaluated. Stratetic and not global peptide to peptoid substitutions were able to either maintain or improve cell permeability.

57. Schlippe YV, Hartman MC, Josephson K, Szostak JW: In vitro selection of highly modified cyclic peptides that act as tight binding inhibitors. J Am Chem Soc (2012) 134:10469-10477. 
58. Yamagata K, Goto Y, Nishimasu H, Morimoto J, Ishitani R, Dohmae N, Takeda N, Nagai R, Komuro I, Suga $\mathrm{H}$, Nureki O: Structural basis for potent inhibition of SIRT2 deacetylase by a macrocyclic peptide inducing dynamic structural change. Structure (2014) 22:345-352.

59. Hipolito CJ, Tanaka Y, Katoh T, Nureki O, Suga H: A macrocyclic peptide that serves as a cocrystallization ligand and inhibits the function of a mate family transporter. Molecules (2013) 18:10514-10530.

60. Kodan A, Yamaguchi T, Nakatsu T, Sakiyama K, Hipolito CJ, Fujioka A, Hirokane R, Ikeguchi K, Watanabe B, Hiratake J, Kimura Y et al: Structural basis for gating mechanisms of a eukaryotic P-glycoprotein homolog. Proc Natl Acad Sci U S A (2014) 111:4049-4054.

61. Davis L, Chin JW: Designer proteins: Applications of genetic code expansion in cell biology. Nat Rev Mol Cell Biol (2012) 13:168-182.

62. Arnison PG, Bibb MJ, Bierbaum G, Bowers AA, Bugni TS, Bulaj G, Camarero JA, Campopiano DJ, Challis GL, Clardy J, Cotter PD et al: Ribosomally synthesized and post-translationally modified peptide natural products: Overview and recommendations for a universal nomenclature. Nat Prod Rep (2013) 30:108160.

63. Blunt JW, Copp BR, Keyzers RA, Munro MH, Prinsep MR: Marine natural products. Nat Prod Rep (2014) 31:160-258.

64. Cragg GM, Newman DJ: Natural products: A continuing source of novel drug leads. Biochim Biophys Acta (2013) 1830:3670-3695.

65. Fujino T, Goto Y, Suga H, Murakami H: Ribosomal synthesis of peptides with - multiple $\beta$-amino acids. Journal of the American Chemical Society (2016) 138:1962-1969.

First example of the incorporation of different $\beta$-amino acids into peptide using the wild-type ribosomes during translation elongation. Until this report, it was believed that the ribosome has a bias against $\beta$-amino acids. Nonetheless, peptides containing multiple $\beta$-amino acids were efficiently synthesized in the FIT system.

66. Dedkova LM, Fahmi NE, Paul R, del Rosario M, Zhang L, Chen S, Feder G, Hecht $\mathrm{SM}$ : $\boldsymbol{\beta}$-puromycin selection of modified ribosomes for in vitro incorporation of $\beta$-amino acids. Biochemistry (2012) 51:401-415.

67. Maini R, Chowdhury SR, Dedkova LM, Roy B, Daskalova SM, Paul R, Chen S, Hecht SM: Protein synthesis with ribosomes selected for the incorporation of $\beta$ amino acids. Biochemistry (2015) 54:3694-3706.

68. Maini R, Nguyen DT, Chen S, Dedkova LM, Chowdhury SR, Alcala-Torano R, Hecht $S M$ : Incorporation of $\beta$-amino acids into dihydrofolate reductase by ribosomes 
having modifications in the peptidyltransferase center. Bioorg Med Chem (2013) 21:1088-1096.

69. Maini R, Dedkova LM, Paul R, Madathil MM, Chowdhury SR, Chen S, Hecht SM:

-• Ribosome-mediated incorporation of dipeptides and dipeptide analogues into proteins in vitro. J Am Chem Soc (2015) 137:11206-11209.

Dipeptides, a thiolated dipeptide analogue and a fluorescent dipeptidomimetic were incorporated into full length DHFR and GFP by mutant ribosomes via chemical aminoacylation/amber codon suppression technology. This is a first example, where cell-free translation system utilized such long amino acids for an elongation event.

70. Hudson GA, Zhang Z, Tietz JI, Mitchell DA, van der Donk WA: In vitro biosynthesis of the core scaffold of the thiopeptide thiomuracin. J Am Chem Soc (2015) 137:16012-16015.

71. Goto Y, Ito Y, Kato Y, Tsunoda S, Suga H: One-pot synthesis of azoline-containing - peptides in a cell-free translation system integrated with a posttranslational cyclodehydratase. Chem Biol (2014) 21:766-774.

Reconstitution of in vitro biosynthetic system for azoline-containing peptides was achieved by integrating a posttranslational cyclodehdrase PatD with the FIT system (FIT-PatD system). Using the FIT-PatD system, several azoline-containing linear peptides were readily synthesized.

72. Torikai K, Suga H: Ribosomal synthesis of an amphotericin-B inspired - macrocycle. J Am Chem Soc (2014) 136:17359-17361.

A macrocyclic peptide analogue of amphoteric-B was sysnthesized using the FIT system. Translation initiation was reprogrammed with a D-cysteinyl derivative having a long hydrophobic chain and spontaneous cyclization between $\mathrm{N}$-chloroacetyl group and a downstream L-cysteine afforded the desired macrocycle. 


\section{Figure captions}

Figure 1. Representative structures of peptide-natural products (PNPs).

Figure 2. Posttranslation cyclization methods. (a) Cyclization between cysteine and dehydroalanine to yield a lanthionine derivative. (b) Macrocyclization via a spontaneous reaction between $N$-chloroacetyl group and cysteine. (c)

Tris(bromomethyl)-benzene-mediated bicyclization on phage displayed peptides. (d) Topologically controlled tricyclization by combining strategies in illustrated (b) and (c).

Figure 3. PNP structural motifs and novel architectures incorporated into ribosomally synthesized peptides via cell free translation.

Figure 4. Natural product-like peptides synthesized via cell free translation. (a) Macrocyclic peptide having four $N$-methylated residues. (b) Peptoid-peptide hybrid. (c) Peptide having different $\beta$-amino acids. (d) Peptide having different backbone heterocyclic motifs. (e) Peptide analogue of Amphotericin-B. Flag = DYKDDDDK. 


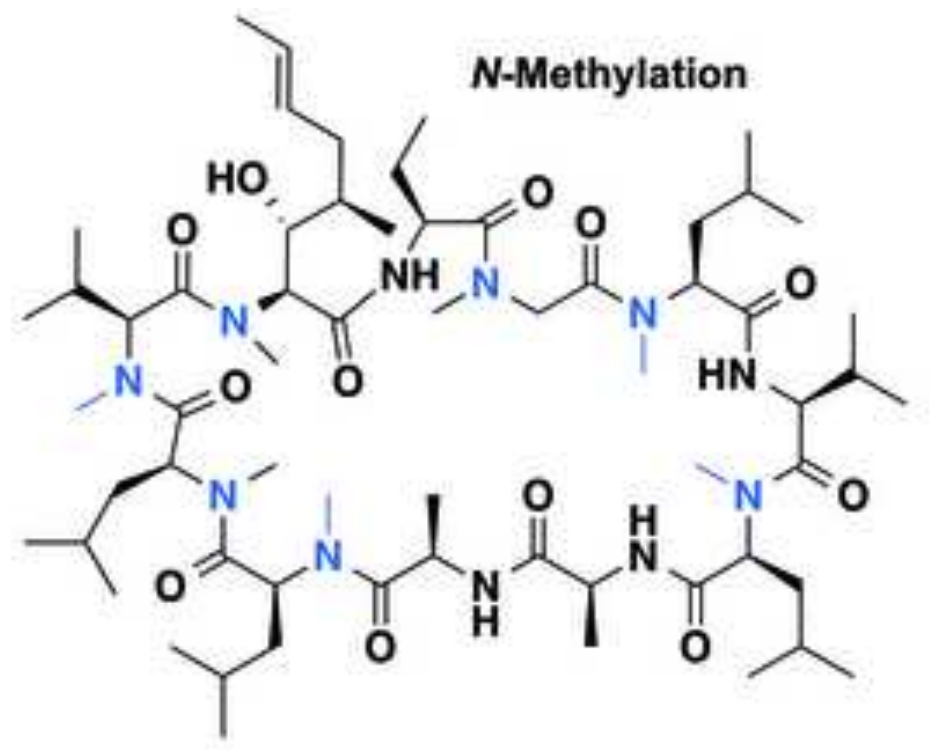

Cyclosporine A

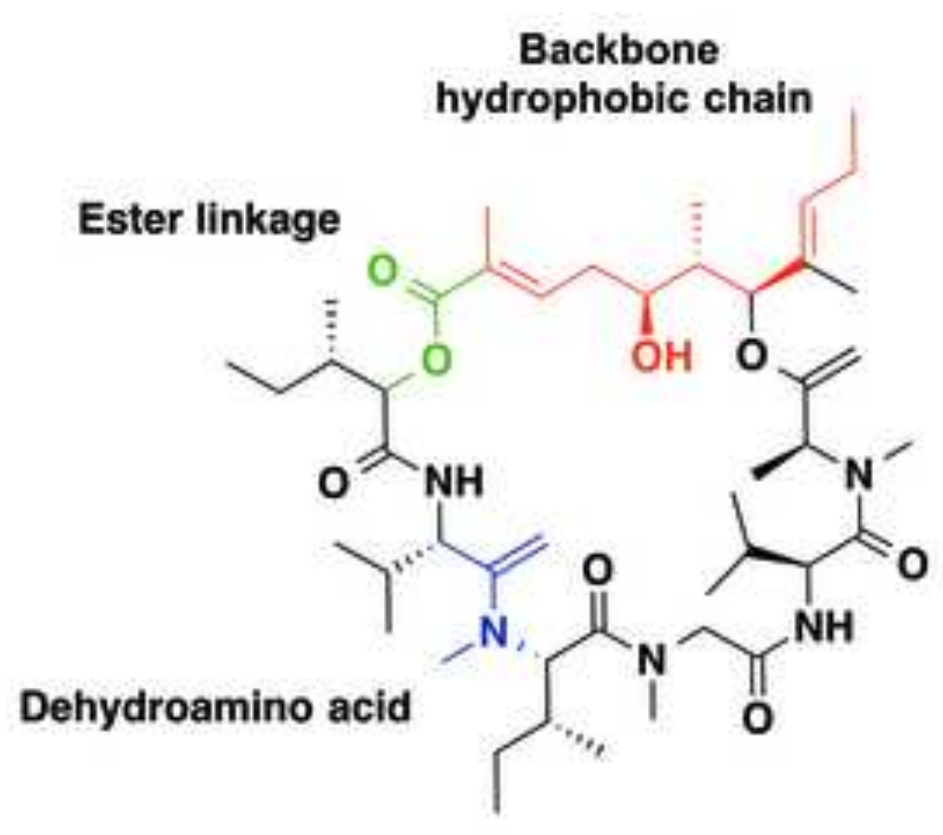

\section{Aurilide}

Non-canonical side chains

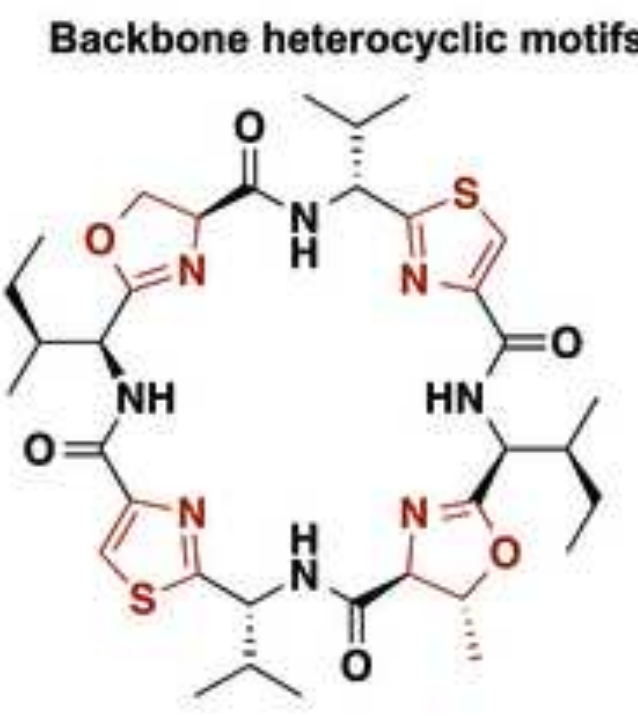

Patellamide A

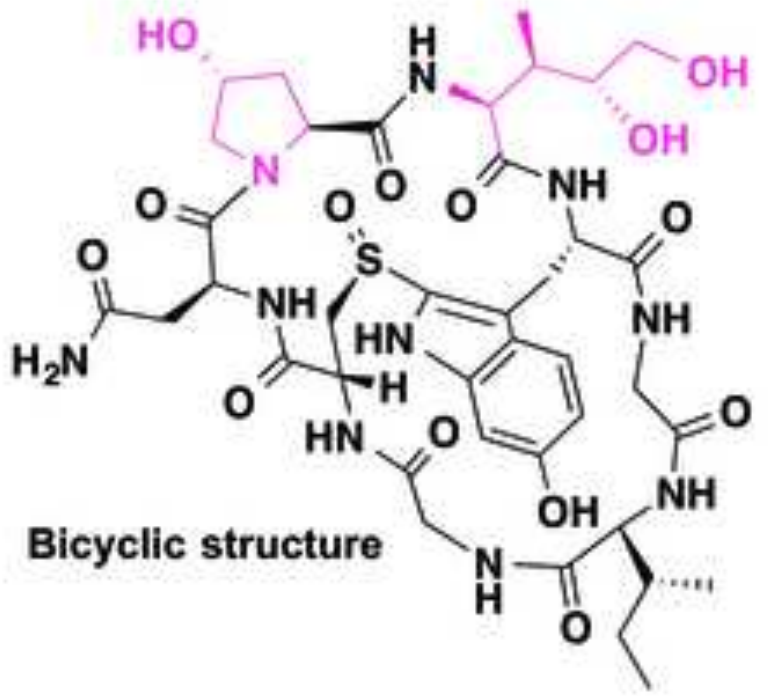

$\alpha$-Amanitin
D-Amino acids

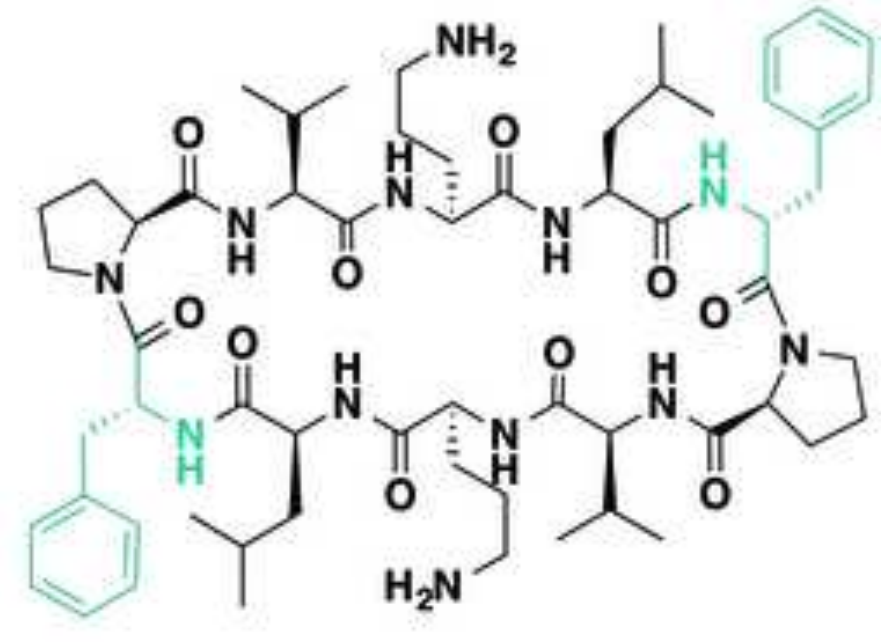

Gramicidin S 
(a)

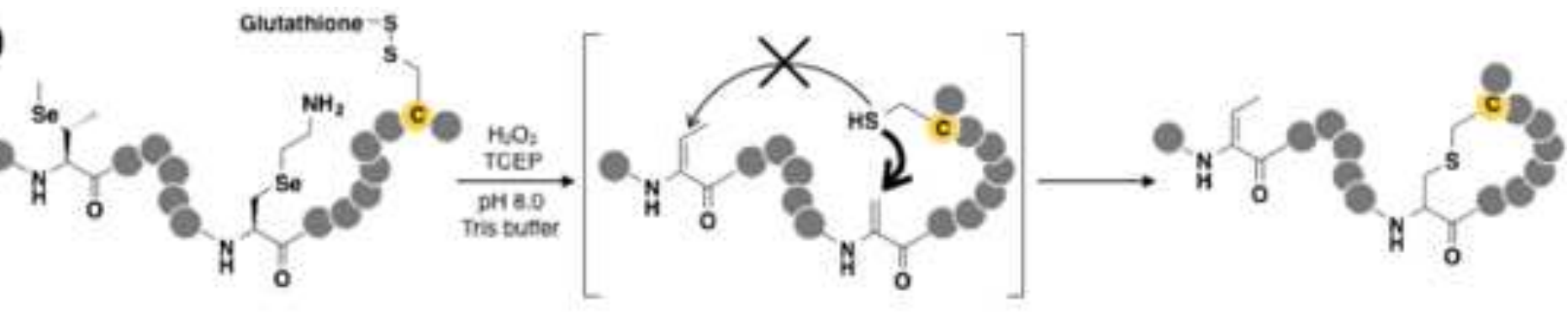

(b)

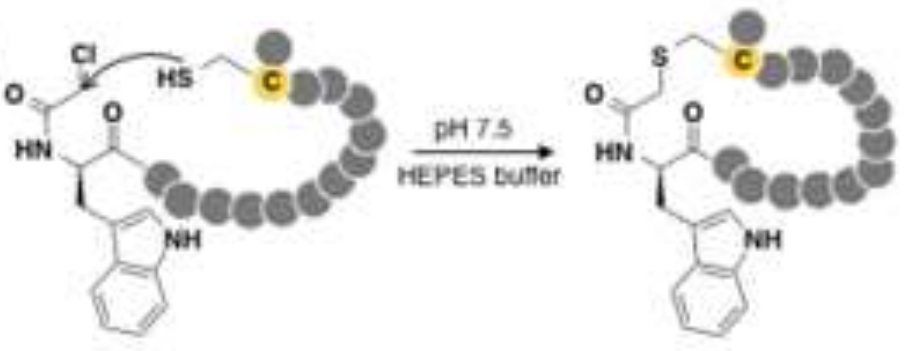

(c)

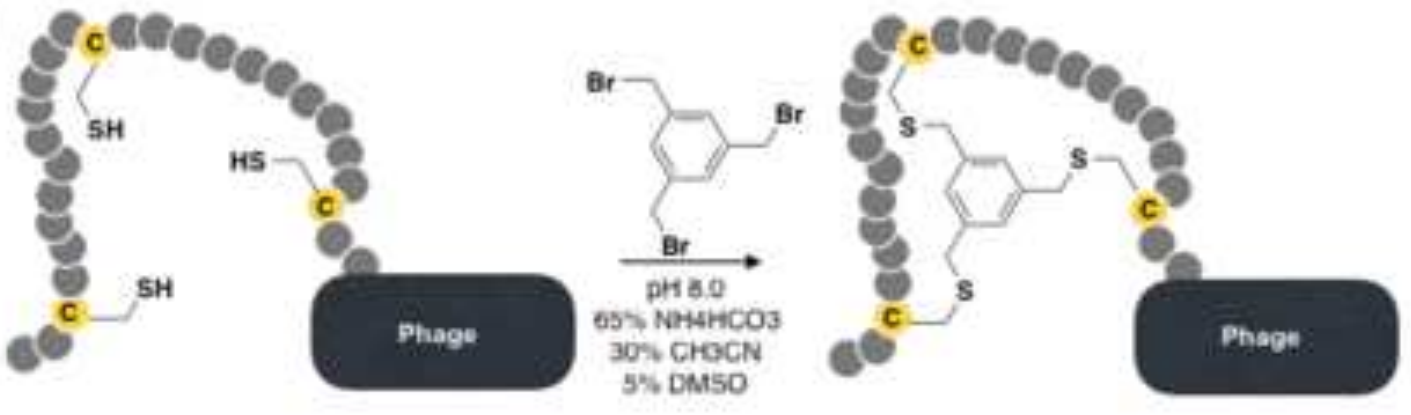

(d)

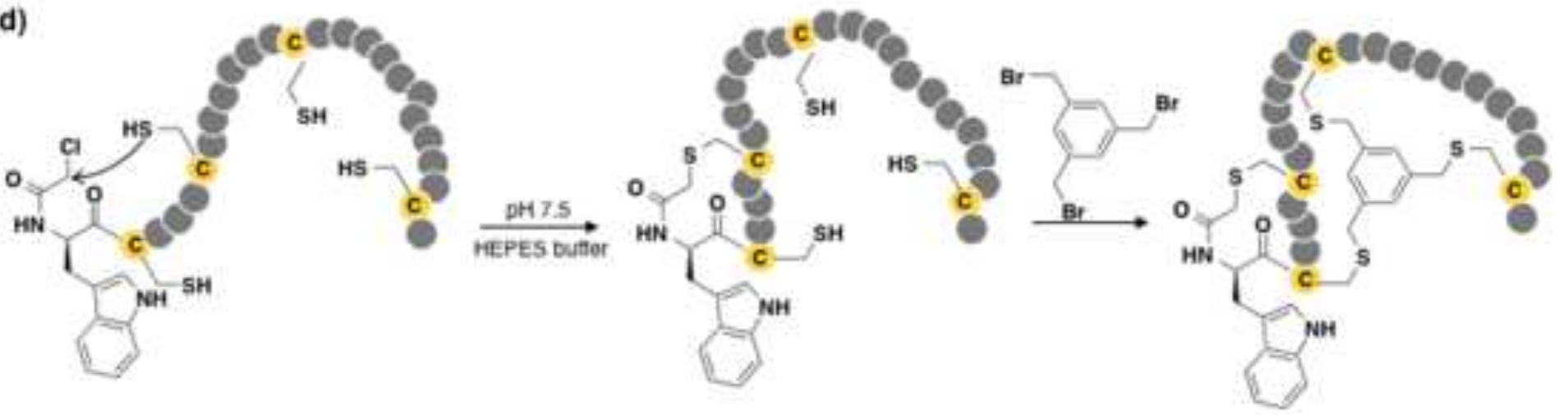




\section{(a) Macrocyclization}

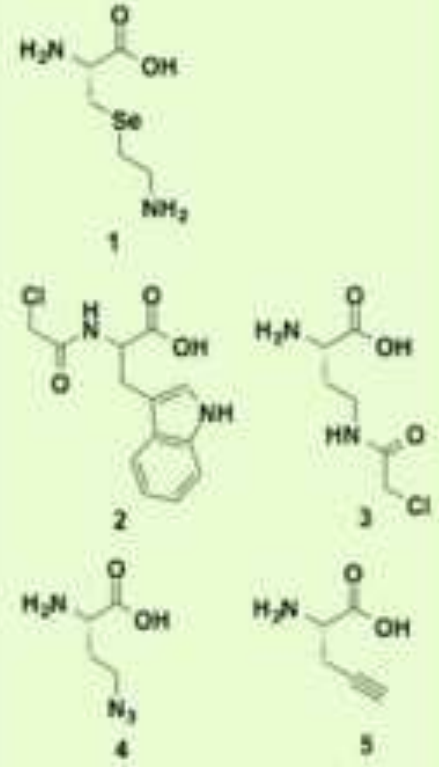

(b) D-amino acids

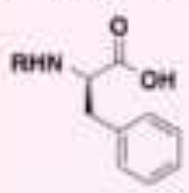

6: $\mathrm{P}=\mathrm{ClCH}_{2} \mathrm{CO}$

E: $\mathrm{R}=\mathrm{H}$ (c) N-Alkyl Amino Acids

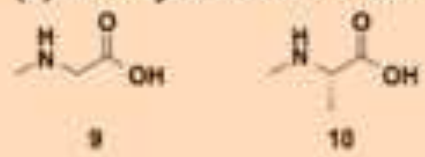

$\mathrm{CH}_{\mathrm{OH}}^{\mathrm{O}}$

$x_{n}{ }^{\circ}$ On a N $\mathrm{N}_{\mathrm{OH}}$

$13: n=0.17: n=4 \quad 21: R=C_{2}$

14: $n=1$ 18: $n=5 \quad 22: R=\mathrm{CH}_{2} \mathrm{OAC}$

$15: n=219: n=6 \quad 22: \mathrm{R}=\mathrm{CO}_{2} \mathrm{CH}_{3}$

t5: $\mathrm{n}=320: \mathrm{n}=\mathrm{T} \quad 24: \mathrm{R}=\mathrm{CN}$

$$
\text { No } \substack{n=1 \\ 25: n=2}_{n=2}^{N} \text { OH }
$$

\section{(d) Other non-canonical amino Acids}
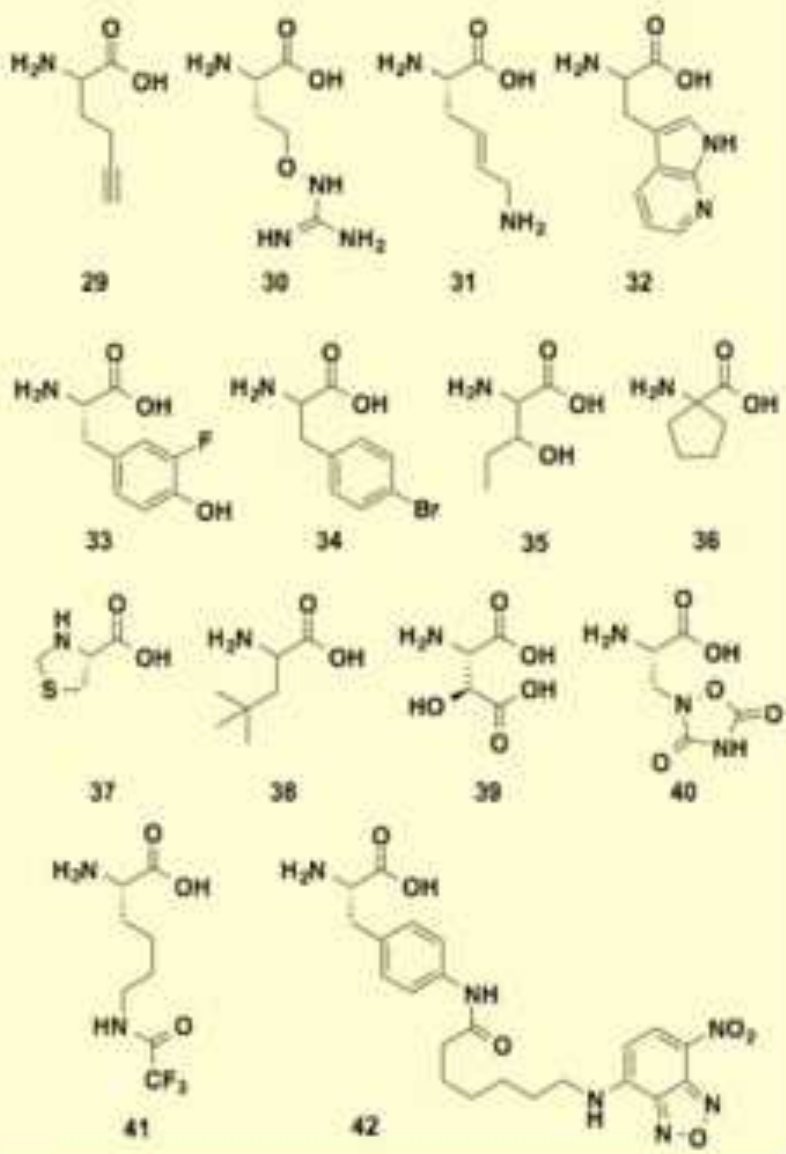

(e) Non- $\alpha$-amino acids

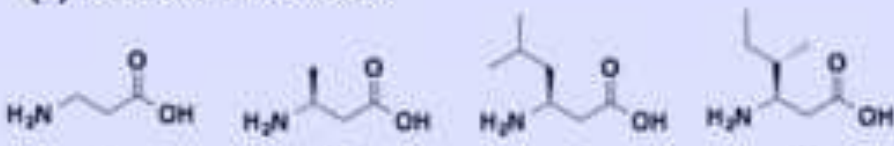

43

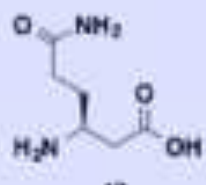

47

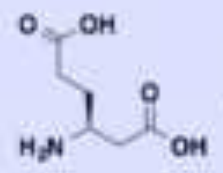

48

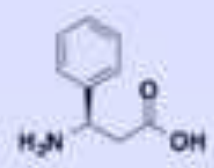

30

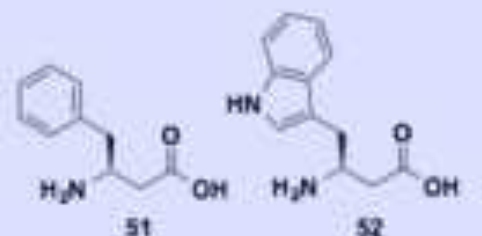

51

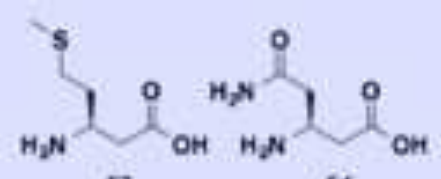

53

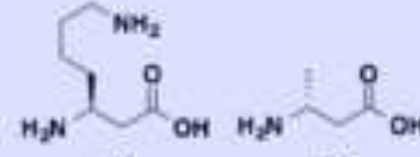

56

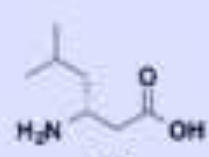

57

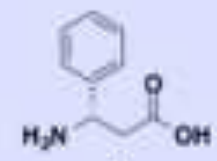

s.

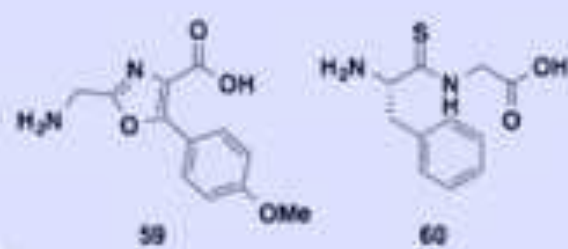

59

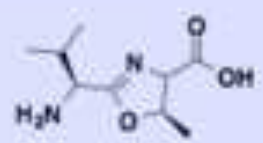

61

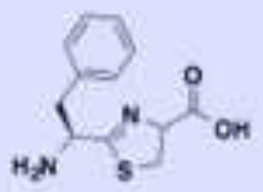

62

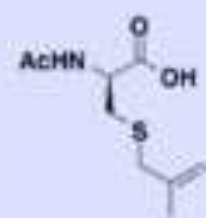


(a)

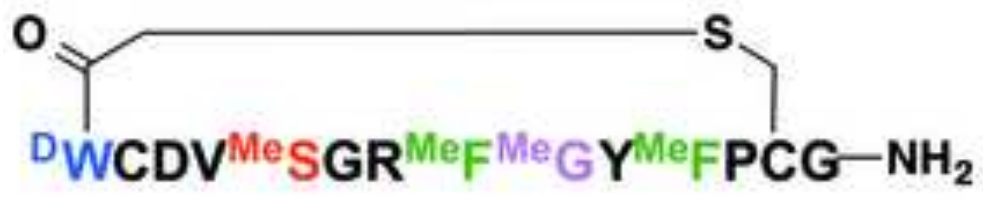

(b)<smiles>C=CCN(CC(=O)N[C@@H](CCCCN)C(=O)[18OH])C(=O)CN(CCCOC(=O)CC)C(=O)CN(CC)C(=O)[C@H](CCSC)NC(N)=O</smiles>

(c)

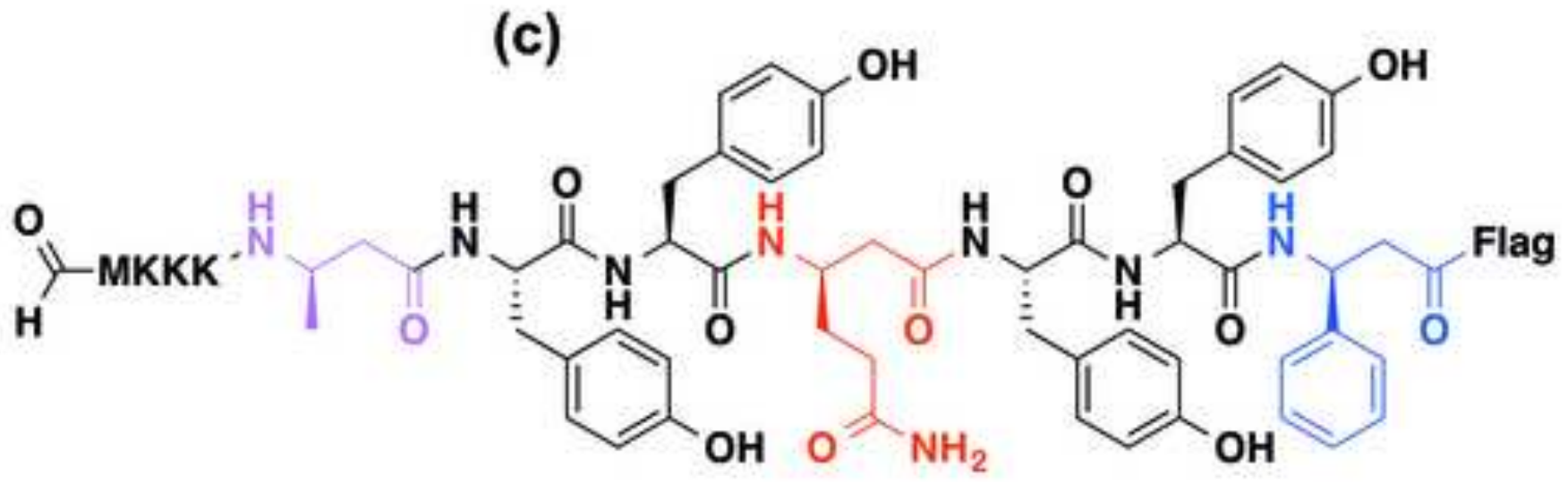

(e)

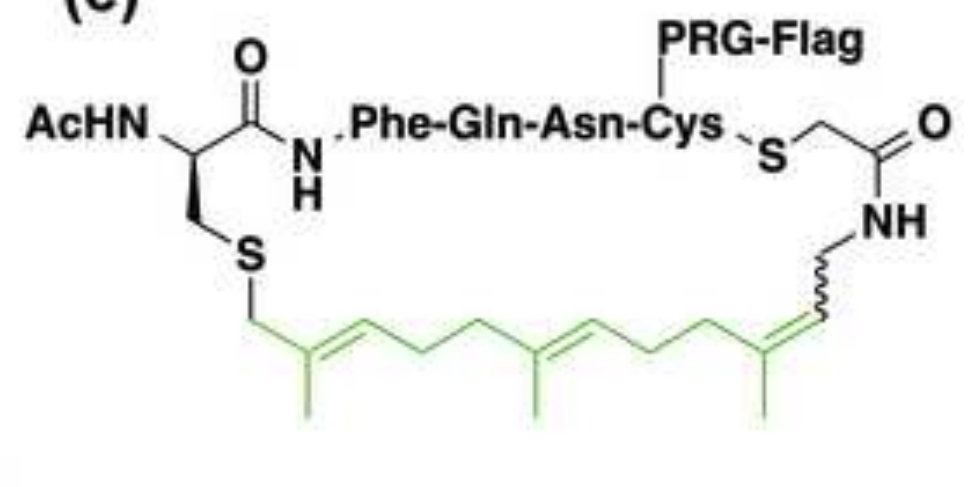

R = MLAELSEEALGDAGGGGG 